\title{
Spontaneously Ruptured Hydatid Liver Cyst with a Presumptive Diagnosis of Acute Appendicitis
}

\author{
Akut Apandisit Ön Tanısılya Opere Edilen Kendiliğinden Rüptüre Karaciğer Kist \\ Hidatik Olgusu
}

Levent Cankorkmaz, Murat Çakar, Gökhan Köylüoğlu

Department of Pediatric Surgery, Faculty of Medicine, Cumhuriyet University, Sivas, Turkey

\section{ABSTRACT}

A 14-year-old female patient with abdominal pain diagnosed as acute abdomen was operated on; a perforated hydatid cyst was found. Hydatid cysts are endemic in Turkey, especially in the eastern and southeastern regions. The liver is the most common location. Ultrasonography and computed tomography can be used in the diagnosis hydatid cysts. Spontaneous intraperitoneal rupture of a hydatid cyst is rare, but it can cause severe anaphylactic reactions and biliary peritonitis. Very few cases have been reported. Though rare, a ruptured hydatid cyst should be considered in the differential diagnosis of acute abdomen in a patient residing in the endemic zone.

Keywords: Acute abdomen, hydatid cyst, spontaneous rupture Received: 23.09.2011 Accepted: 04.01.2012

Available Online Date: 20.05.2013

\section{ÖZET}

Akut batın ön tanısıyla ameliyat edilen ve perfore kist hidatik saptanan 14 yaşında kız olgu sunulmuştur. Kist hidatik Türkiye'de özellikle Doğu ve Güneydoğu bölgelerinde endemiktir. En sık yerleşim lokalizasyonu karaciğerdir. Ultrasonografi ve bilgisayarlı tomografi kist hidatiğin tanısında kullanılabilir. Kistin kendiliğinden periton içine rüptürü ciddi anaflaktik reaksiyonlara ve safra peritonitine neden olabilen oldukça ender ancak ciddi bir komplikasyondur. Çok az olgu bildirilmiştir. Nadir olmasına rağmen, rüptüre kist hidatik endemik bölgede bulunan bir hastada akut karın ayırıcı tanısında düşünülmelidir.

Anahtar Kelimeler: Akut batın, kist hidatik, kendiliğinden rüptür Geliş Tarihi: 23.09.2011 Kabul Tarihi: 04.01.2012

Çevrimiçi Yayın Tarihi: 20.05.2013

\section{Giriş}

Kist hidatik (KH) Türkiye'de özellikle Doğu ve Güneydoğu bölgelerinde endemiktir (1). En sık tutulan organlar karaciğer (KC) ve akciğer olmakla birlikte vücudun her yerinde görülebilir. Ultrasonografi ve bilgisayarlı tomografi KH tanısında kullanılan radyolojik tetkiklerdir (2). Hayvan besleyen toplumlarda sık görülür (3). İnsanlar, infekte köpeklerle temas, kontamine yiyecekler, su veya toprakta bulunan yumurtaların ağızdan alımı ile infekte olur. Parazit yerleştiği organda büyüyerek içi sıvı dolu kistler meydana getirir (4).

Kistin travma ya da kist basıncının artması nedeniyle kendiliğinden rüptürü ender ama ciddi bir komplikasyondur. Periton içine rüptür sonucu, antijenik içeriğin sistemik dolaşıma karışmasıyla anafilaktik reaksiyon ya da safra peritoniti gelişebilir (5). Bu yazıda akut batın ön tanısıyla opere edilen kendiliğinden rüptüre olmuş KC kist hidatik olgusu sunulmuştur.

\section{Olgu Sunumu}

On dört yaşında kız bir gün önce başlayan karın ağrısı ve kusma yakınmasıyla acile başvurdu. Hastanın öyküsü, ağrının yaygın başlayıp sonra sağ alt kadrana lokalize olduğu şeklindeydi. Travma öyküsü yoktu. Fizik muayenesinde batın hassasiyeti ve defans mevcut idi. Ultrasonografi raporu; apendiksin 6 mm, nonperistaltik, nonkompresible olduğu, barsaklar arasında minimal ser- 


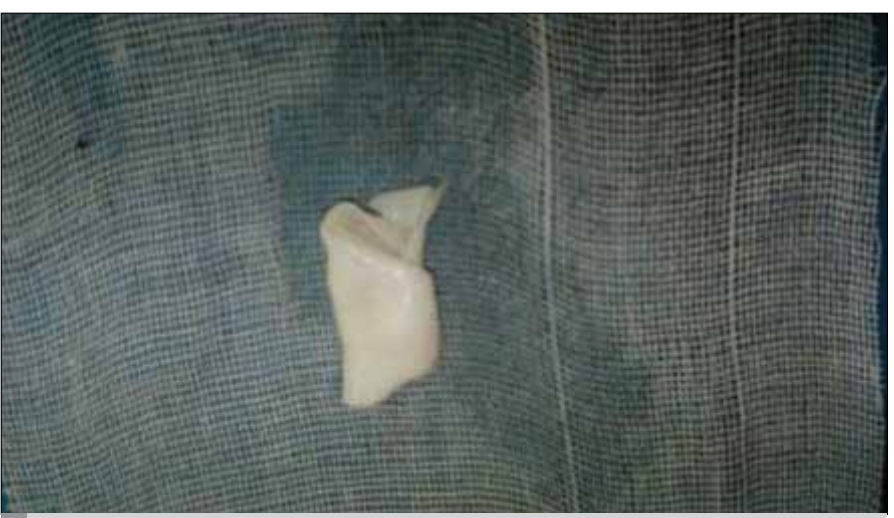

Resim 1. Hidatik kistin makroskopik görünümü

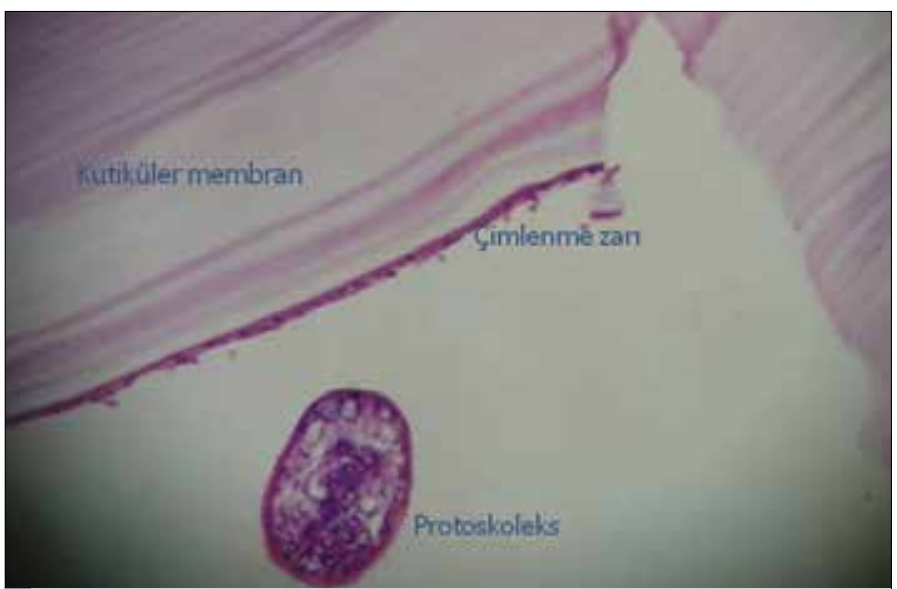

Resim 2. Hidatik kistin mikroskopik görünümü (H-E;x200)

best sıvı bulunduğu şeklindeydi. Laboratuvar tetkiklerinde; lökosit: 24,700 mm³ , eosinofil: \%1,0, CRP: 2,69 mg/L (0-8 mg/L normal sınırlar), KC fonksiyon testleri ve bilirubin değerleri normaldi. Hasta bu bulgularla akut batın (akut apandisit) ön tanısıyla acil operasyona alındı.

Eksplorasyonda apendiks salim olarak değerlendirildi, ancak batında açık sarı renkli safra saptanınca, eksplorasyona devam edildiğinde, KC sağ lob diyafram komşuluğunda safra kaçağı olan perfore KH saptandı. Karaciğerde ve batın içinde başkaca bir patolojiye rastlanmaması üzerine kistektomi ve safra kaçağı onarımı yapılarak loja bir adet boru dren konulup operasyon sonlandırıldı. Kist içeriğinin makroskobik görünümü Resim 1'dedir. Olgunun postoperatif dönemi sorunsuzdu ve safra kaçağı olmadı. Kistin mikroskobik görünümü Resim 2'de görülmektedir. Albendazol (10 mg/Kg/gün) başlanan olgunun postop 6. ayında medikal tedavisi devam etmekte olup herhangi bir sorunu yoktur.

\section{Tartışma}

Ülkemiz gibi endemik bölgelerde KH tanısı sorun olmaya devam etmektedir. Çeşitli mikroskobik testler ve eozinofili tanıya yardımcı olsa da özgül değildir (6). Büyük boyutlara ulaşan veya komplike KH'ler visseral organlara, biliyer sisteme ya da toraksa rüptüre olabilir. Rüptür kistin boyutlarını artması, travma ve öksürük gibi basınç artışına yol açan sebeplerden olabilir (7). KH bulgu ve belirtileri kistin yerleşim yeri, büyüklüğü, diğer organlarla ilişkisi ve komplikasyon varlığına bağlı olarak değişkenlik gösterir (8). Literatürde karaciğer, dalak, pankreas, mezenterik ve retrovezikal kistlerin gastrointestinal sisteme rüptüre veya fistülize olmasıyla barsak tıkanıkları bildirilmiştir $(8,9)$. Kistin periton içine rüptürü ciddi anaflaktik reaksiyonlara neden olabilir (\%1-2,5). Olgumuzda herhangi bir alerjik reaksiyon bulgusu (ürtiker, kaşıntı, solunum sıkıntısı vb.) ve eozinofili yoktu. KC kist hidatiğini düşündürecek öykü, laboratuvar ve radyolojik bulgu saptanmadı. Hastanın US raporunun ve fizik muayenesinin akut apandisitle uyumlu olması durumunda başka bir görüntüleme yöntemine gerek görülmemiştir. Olguda KC'deki perfore kistik yapının saptanamamasının en önemli nedeninin, akut batın ön tanısıyla yapılan US'de radyoloğun çoğunlukla alt kadranlara yoğunlaşması olduğunu düşünmekteyiz. Bu nedenle radyolojik olarak yapılacak akut batın ayıııcı tanısında tüm batın kadranlarının aynı titizlikle değerlendirilmesinin önemi ortaya çıkmaktadır.

Periapandisit apandiksin iç katmanlarına yönelen ve serozit şeklinde tanımlanabilecek bir durumdur ve nedenlerinden birisi de apendiks harici batın içi bir patolojiler (10). Klinik olarak akut apandisit tablosuyla başvuran hastaların \%5,4'ünde periapandisit saptandığı rapor edilmiştir (10). Ameliyatta apendiksin normal olarak değerlendirilmesine rağmen ultrasonografi ve fizik muayene bulgusunun akut apandisitle uyumlu olmasının nedeninin periton içindeki safraya bağlı periapandisit olabileceğini düşünmekteyiz. US'de apandisit çapının sınırda olmasına rağmen makroskobik olarak belirgin akut apandisit hali saptanmaması nedeniyle apendiks normal olarak değerlendirilerek apendektomi uygulanmamışır. Post-op dönemde herhangi bir sorunla karşılaşılmaması bu bulguyu destekler görünmektedir.

\section{Sonuç}

Akut batın tablosundaki bir hastada yapılan ultrasonografik değerlendirmede sadece sağ alt kadranın değil, tüm batının dikkatli bir şekilde incelenmesi ameliyatın planlanması ve ayıııcı tanıda önemli olacaktır. Ultrasonografi bulgularına göre gerekirse faklı radyolojik tetkiklerle tanıya gidilebilir. Ülkemizin endemik durumu göz önüne alındığında ender de olsa KC kist hidatik rüptürü de akut batın ayıııcı tanısında akılda tutulması gereken bir durumdur.

\section{Conflict of Interest}

No conflict of interest was declared by the authors.

Peer-review: Externally peer-reviewed.

\section{Author Contributions}

Concept - L.C.; Design - L.C.; Supervision - L.C., G.K.; Funding - L.C.; Materials - L.C.; Data Collection and/or Processing - L.C., M.C.; Analysis and/or Interpretation - L.C.; Literature Review - L.C., M.Ç.; Writer - L.C.; Critical Review - L.C., G.K.

\section{Çıkar Çatışması}

Yazarlar herhangi bir çıkar çatışması bildirmemişlerdir. 
Hakem değerlendirmesi: Dış bağımsız.

\section{Yazar Katkıları}

Fikir - L.C.; Tasarım - L.C.; Denetleme - L.C., G.K.; Kaynaklar - L.C.; Malzemeler - L.C.; Veri toplanması ve/veya işlemesi - L.C., M.Ç.; Analiz ve/veya yorum - L.C.; Literatür taraması - L.C., M.Ç.; Yazıyı yazan - L.C.; Eleştirel Inceleme - L.C., G.K.

\section{Kaynaklar}

1. Pekcici MR, Canlı AB, Uyanık I, İnceköy M. Abdominal kist hidatik olgularımızın retrospektif değerlendirilmesi. Tıp Araştırmaları Dergisi 2004; 1: 5-10.

2. Semelka RC, Shoenut JP, Kroeker MA, Greenberg HM, Simm FC, Minuk GY, et al. Focal liver disease: comparison of dynamic contrast-enhanced CT and T2-weighted fatsuppressed, FLASH, and dynamic gadolinium- enhanced MR imaging at 1. 5 T. Radiology 1992; 184:687-94.

3. Ünlü Y, Ceviz M, Karaoğlanoğlu N, Becit N, Koçak H. Arterial embolism caused by a ruptured hydatid cyst in the heart: report of a case. Surg Today 2002; 32: 989-91. [CrossRef]
4. Morar R, Feldman C. Pulmonary echinococcosis. Eur Respir J 2003; 21: 1069-77. [CrossRef]

5. Akcan A, Akyildiz H, Artis T, Ozturk A, Deneme MA, Ok E, et al. Peritoneal perforation of liver hydatid cysts: clinical presentation, predisposing factors, and surgical outcome. World J Surg 2007; 31: 1284-91. [CrossRef]

6. Sanli M, Tunçözgür B, Elbeyli L. Pulmonary hydatid disease and surgical therapy. Turk J Thorac Cardiovasc Surg 2000; 8: 703-5.

7. Balci $A E$, Eren N, Eren S, Ülkü R. Ruptured hydatid cysts of the lung in children: clinical review and results of surgery. Ann Thorac Surg 2002; 74 889-92. [CrossRef]

8. Onur E, Köksal N, Uzun MA, Sümer A, Altınlı E, Çelik A. Mekanik intestinal obstrüksiyona neden olan ekstrahepatik intraabdominal dev kist hidatik. Bakırköy Tıp Dergisi 2006; 2: 28-30.

9. Ozturk G, Aydinli B, Yildirgan Ml, Basoglu M, Atamanalp SS, Polat KY, et al. Posttraumatic free intraperitoneal rupture of liver cystic echinococcosis: a case series and review of literature. Am J Surg 2007; 194: 313-6. [CrossRef]

10. Cankorkmaz L, Özer H, Köylüoğlu G. Over torsiyonu ve peri apandisit birlikteliği. Cumhuriyet Tıp Derg 2011; 33: 378-81. 